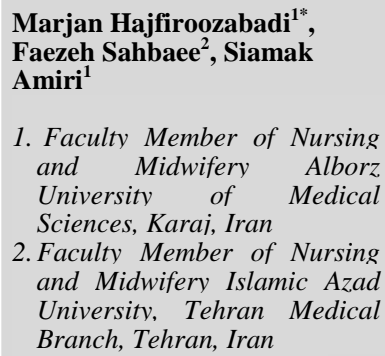

\section{The Effect of Hata Yoga on Mental Health of Women Referring to Yoga Training Centers in Tehran}

Received: 10 Dec. 2017 ; Accepted: 22 May 2018

\section{Abstract}

Background: Mental health problems, including Depression and Anxiety and other mental disorders, will be one of the major problems of human societies in the coming years. One of the ways to prevent and promote mental health is to use yoga exercises. The Aim of this study was to investigate the effect of yoga on mental health of women referred to Yoga centers in Tehran.

Materials and Methods: This research is a quasi-experimental study that was performed on 100 women referred to yoga training centers in Tehran. Participants were recruited from 20 centers of Yoga teaching in Tehran with convenient sampling . The data gathering tool was a questionnaire that was put at before and one month after training of Hata yoga.

Results: The results that obtained from analyzing data show that the mean scores of areas of physical symptoms and social dysfunction increased significantly a month after the training of yoga exercises. Also, the mean scores of depression and anxiety and sleep disorders were significantly decreased, and as a result, the average of general health after education was significantly increased.

Conclusion: The eight-session of Yoga after one month may be effective in improving the mental health of women participating in the study.

Keywords: Yoga, Hata yoga, Mental Health, Women, Tehran, General Health 


\section{بررسى تأثير هاتا يوكا بر سلامت روان زنان مراجعه كننده به مراكز آموزش يوكا شهر تهران}

تاريخ دريافت مقاله؛ 99/9/19؛ تاريخ بذيرش:9V/T/19

حكک1.

زمينه و هدف: مشكلات سلامت روان از جمله افسردكى و اضطراب و ديخر اختلالات روانى يكى از بزركترين مشكلات

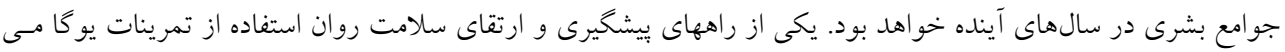

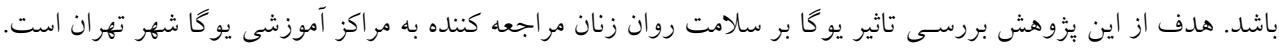

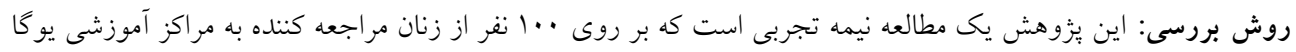

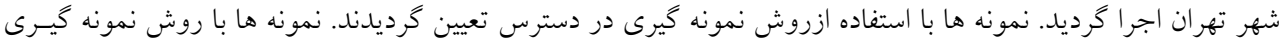

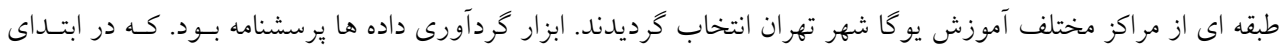
آموزش و يكى ماه يّ از آموزش در اختيار شركت كنند مان قرار داده شد.

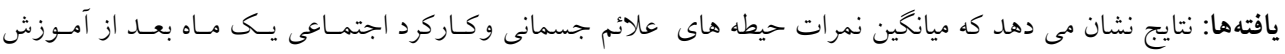

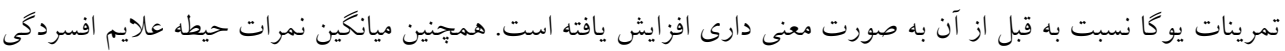

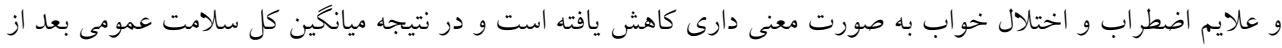
آموزش به صورت معنى دارى افزايش يافته است.

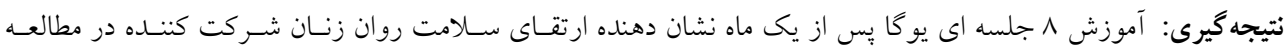
كرديد. كلمات كليدى: يو گا، هاتا يو گا، سلامت روان، زنان، تهران، سلامت عمومى

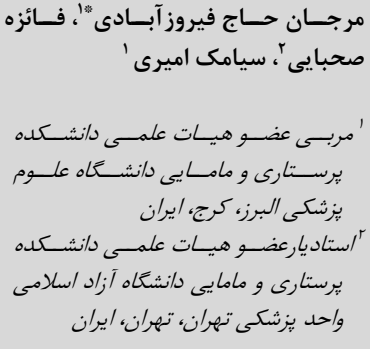

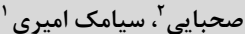

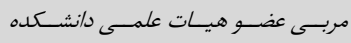

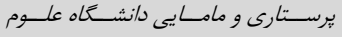

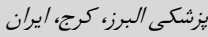

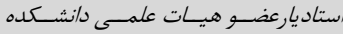

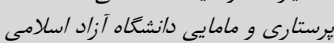
واحد بزشكى تهران، تهران، ايران

*نويسنده مسئول:

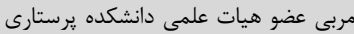

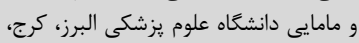
يران

.rQ-rKT.G..

E-mail: m.firoozabadi12@gmail.com 
اضطرابى، اسكيزوفرنى و ديخر اختلالات مورد بررسى قرار گرفت

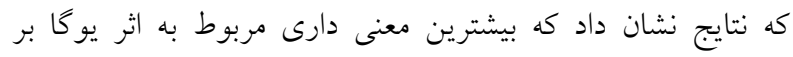

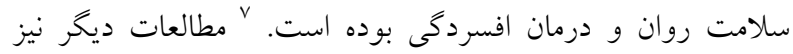

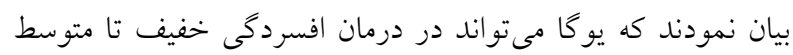

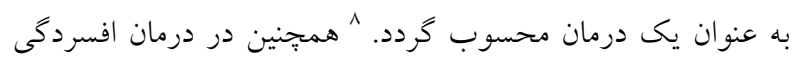

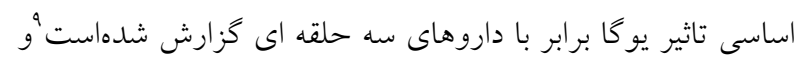

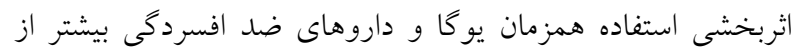
مصرف داروهاى ضد افسردگى به تنهايى مىباشد. '.

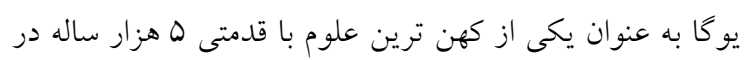
عصر تكنولوزى امروز همجنان در حال گسترش و مورد استقبال عموم است يوكا آرامش روانى و تعادل و هماهنكى اركان تن و و

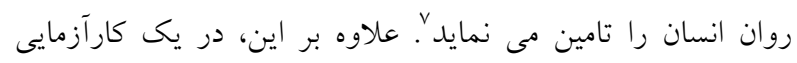
تصادفى بر روى اثرات مداخله يوكا در ه" بيمار مبتلا به لنفوم،

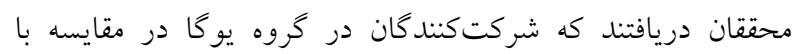

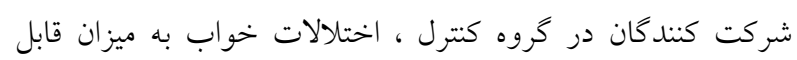
توجهى كمتر، كيفيت زندگى ذهنى بهتر، زمان خواب سريعتر، طول دوره خواب بيشتر و مصرف داروهاى خواب در طول بيخيرى كمتر بود" در يك مطالعه ديخر، كروه تحقيقاتى دريافتند كه يس از و 9 ماه

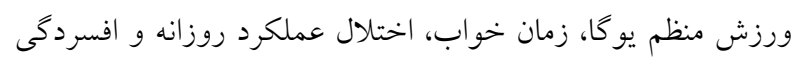
1YN فرد بزر خسال در سنين مختلف كاهش مى يابد و كيفيت خواب ذهنى، ادراك سلامت جسم و سلامت روان بهبود مى يابد. در بخش هاتايوكا كه آساناها يا وضعيت هاى يوكا انجام مى گيرد تمرين كننده سعى در تمركز بر روى عضو در حال كشش

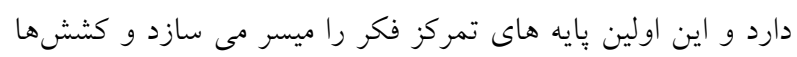

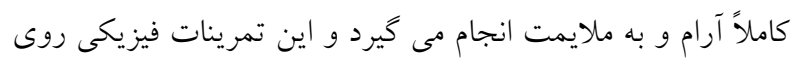

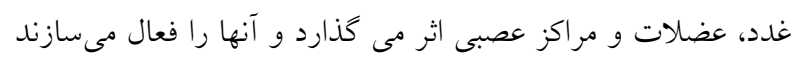
و باعث سلامت بدن نشاط مى شود.

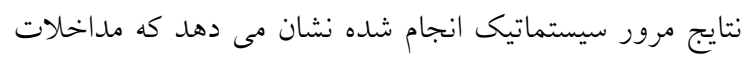

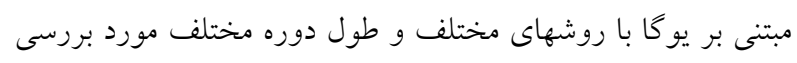

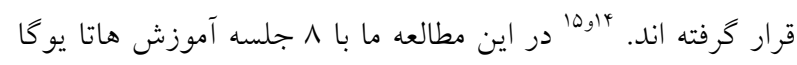
بر روى زنان مراجعه كننده به مراكز آموزش يوكا شهر تهران، تاثير

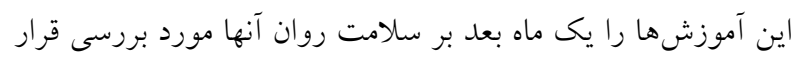

مشكلات سلامت روان از جمله افسردكى و اضطراب و ديخر اختلالات روانى بزركترين مشكلات جوامع بشرى در سالهاى

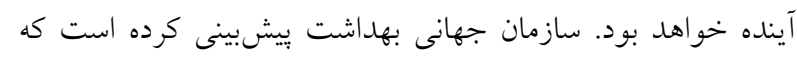

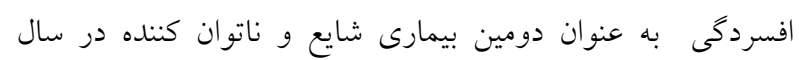

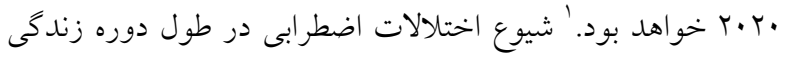

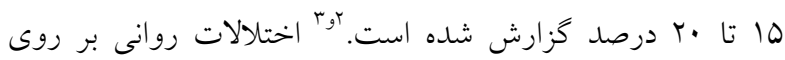
شناخت، احساس و كنترل رفتار فرد تاثير مى كذارد و باعث اختلال در عملكرد فرد در خانواده و اجتماع مى گردد. ارتقاى بهداشت روان فرايندى است كه مردم را قادر مى سازد ودرد تا كتترل بيشترى بر سلامتى خود داثته باشند. عوامل روانى اجتماعى، تغذيه مناسب، عدم مصرف سيخار و الكل، اجتناب از رفتارهاى بر خطر جنسى، ورزش كافى و... بر ارتقاى سلامت تأثير مثبت دارند. تحقيقات نشان مى دهد كه روش هايى مانند يوكا، ورنى تاى جى، طب سوزنى، تن آرامى و معنويت در كاهش هورمونهاى مرتبط با استرس و افسردكى(كورتيزول، ايى نفرين و نور ايى

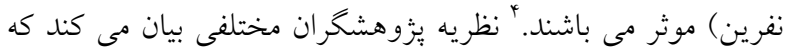
تاثير يوكا از طريق سيستم عصبى و قلب و عروق و تركيب زنى اعمال مى گردد.تحريك عصب واگ باعث افزايش فعاليت پاراسيمياتيك سيستم عصبى اتونوميك و همجنين افزايش فعاليت كاما آمينوبوتريك اسيد (انتقال دهنده عصبى) در مغز مىشودهـ. فرض بر اين است كه تمرينات يوكا كم كارى سيستم اعصاب

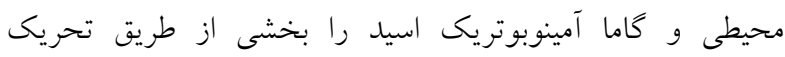
اعصاب واق و بخشى ديخر از را طريق كاهش بار فرايند ايجاد ثبات درونى (آلواستاتيك) كه باعث تسكين علايم مى شود اصلاح

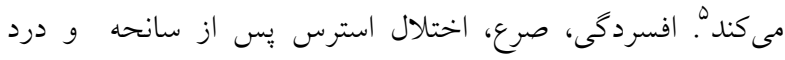

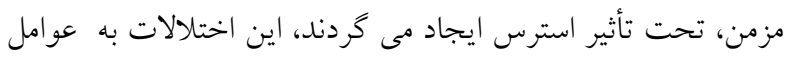
دارويى كه فعاليت سيستم كابا را افزايش مى دهند، يّاسخ مثبت

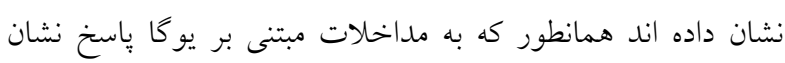
مى دهند. 0 در مطالعه مرور سيستماتيك كه به بررسى مقالات سالهاى

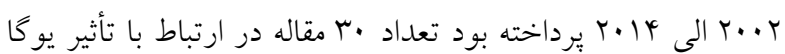
بر اختلالات سلامت روان مانند افسردكى اساسى، اختلالات 


\section{روش اجرا}

مواد و روشها

براى گردآورى داده ها در اين يُوهش يس از كسب اجازه از

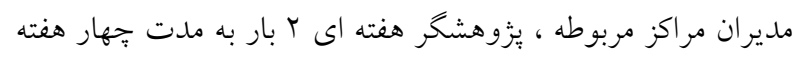
در محيطهاى يزوهش حضور يافت، يرونده هاى ثبت نام افراد را

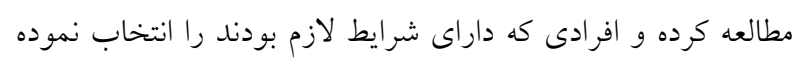

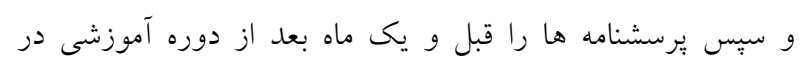

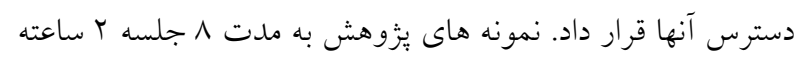

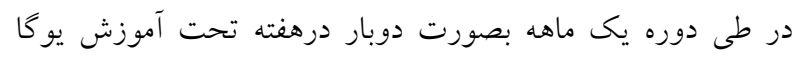
قرار كرفتند. از شركت كنندكان رضايت نامه شركت در در مطالعه

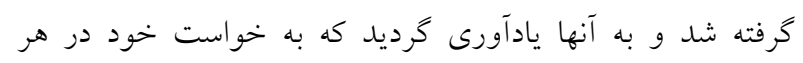
مرحله از مطالعه مى توانند از مطالعه خارج شوند.

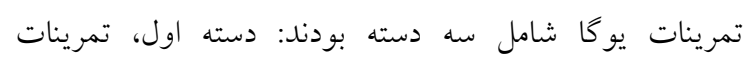

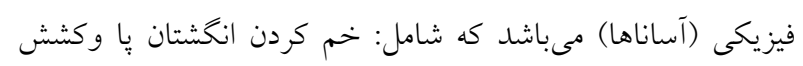

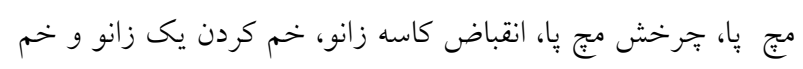

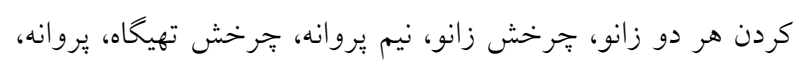

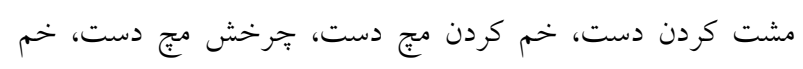

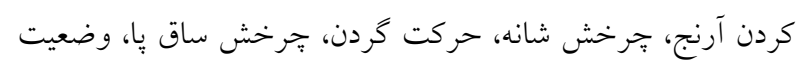

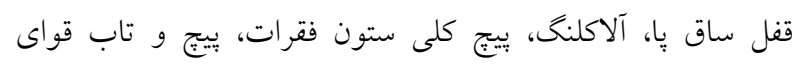

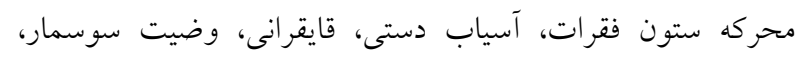

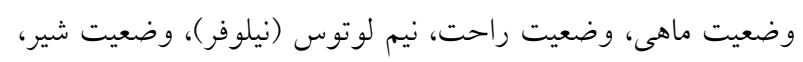

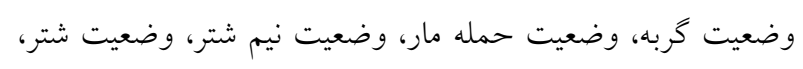
وضعيت درخت خرما، وضعيت مثلث و سلام بر خورشيد مى باشد.

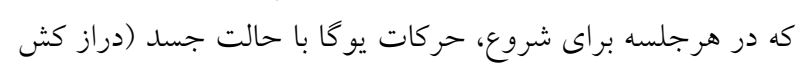

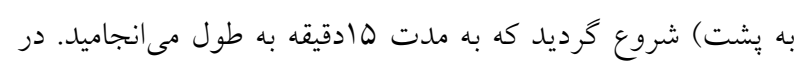

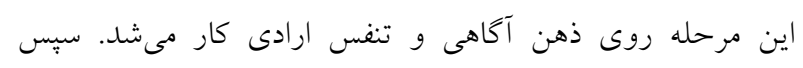

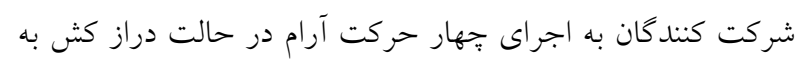
همراه تمركز ذهنى روى عضو مورد نظر تشويق مى شدند. در ادامه

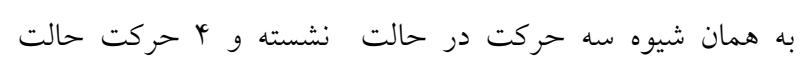

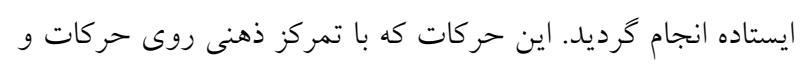

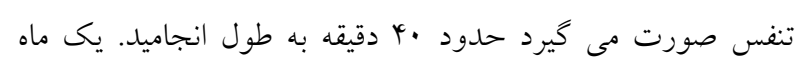

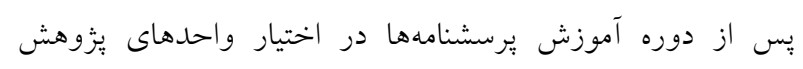
قرارداده شد.

دومين جز از تمرينات كاربردى يو گا، تمرينات تنفسى مىباشد.

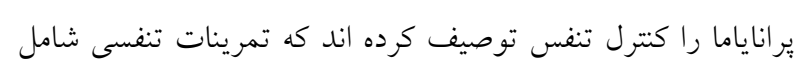

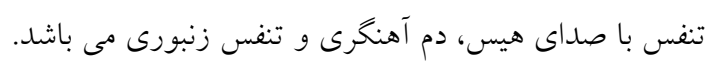

اين مطالعه از نوع نيمه تجربى و به صورت قبل و بعد مى باشد

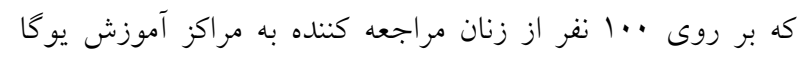

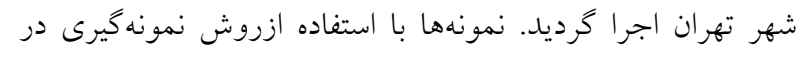

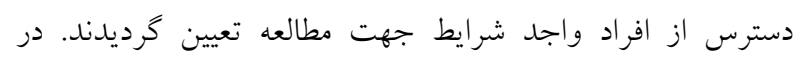

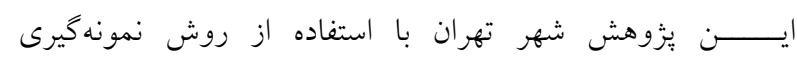
تصادفى - طبقه اى به ه منطقه شمال ، جنوب، شرق، غرب و و مركز

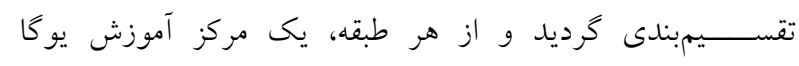

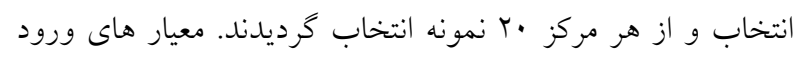

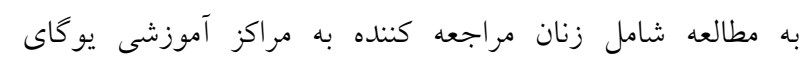

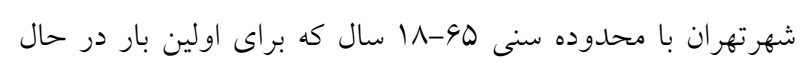

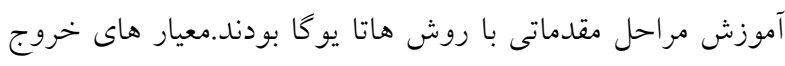
از مطالعه شامل ابتلا به اختلالات روان يزشكى، مصرف داروهاى روان يزشكى، ابتلا به بيمارىهاى زمينهاى موثر بر روان مثل تيروئيد

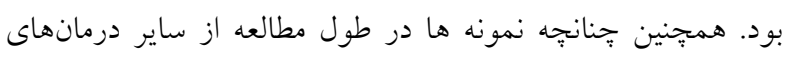

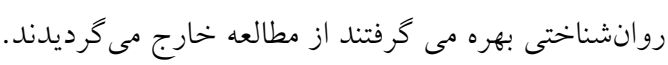

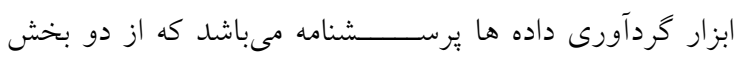
تشكيل شده است كه بخش اول مربوط به اطلاعات دموگرافيك و بخش دوم يرسشنامه سلامت عمومى (GHQ-28) بود. يرسشنامه دمو گر افيك شامل IV سوال بود كه جهت روايى آن از روش اعتبار محتوى استفاده گرديد. بدين صورت كه يّ از بررسى متون كويه ها در در اختيار جمعى از صاحب نظران قرار گرفت و يس از از اعمال تغييرات مورد استفاده قرار گرفت. جهت تعيين سلامت روان نمونه هاى يزوهش از يرسشنامه سلامت عمومى نسخه r بو سوالى استفاده كرديد. اين برسشنامه توسط كلدبرى و هيلر (19V9) ارائه شده و و

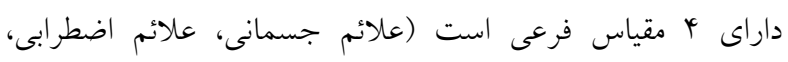

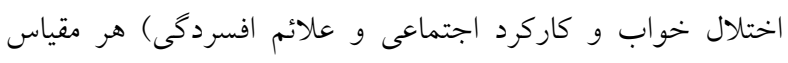
داراى V Vويه مىباشد. اين يرسشنامه در ايران مورد هنجاريابى و و

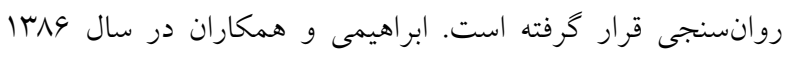

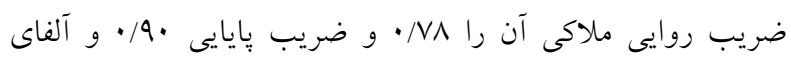
كرونباخ 9V/ • درصد كزارش نمودند. 


\begin{tabular}{|c|c|}
\hline & 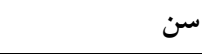 \\
\hline$\%$ \% & $\mid \Lambda-r \cdot$ \\
\hline$\%$ & rl-r. \\
\hline$\%$ & $41-0$. \\
\hline \multirow[t]{2}{*}{$\%$} & بيشتر از •0 \\
\hline & وضعيت تاهل \\
\hline$\% \Delta \Lambda$ & متاهل \\
\hline$\%$ \% & مجرد \\
\hline$\%$ & مطلقه \\
\hline \multirow[t]{2}{*}{$\%$} & بيوه \\
\hline & اشتغال \\
\hline$\% .9 \cdot .9$ & شاغل \\
\hline$\% 49.9$ & خانه دار \\
\hline \multirow[t]{2}{*}{$\% 1 r / 0$} & بيكار \\
\hline & تحصيلات \\
\hline$\%$ & 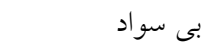 \\
\hline$\%$ & 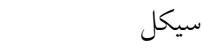 \\
\hline$\%$ & دييلم و فوق دييلم \\
\hline$\%$ & ليسانس و بالاتر \\
\hline \multicolumn{2}{|c|}{ فعاليت فيزيكى حداقل دو بار در هفته } \\
\hline$\% .9 \mathrm{~V}$ & و ارزشكار \\
\hline \% & وزرش نمى كند \\
\hline
\end{tabular}

نتايج بعد اختلال در عملكرد اجتماعى سلامت عمومى، قبل و بعد

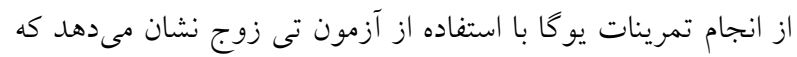

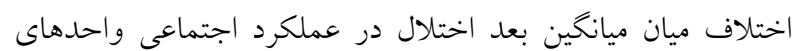

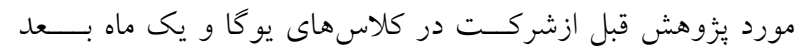

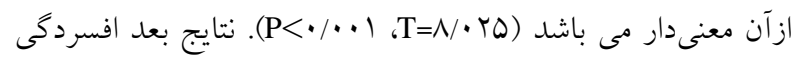

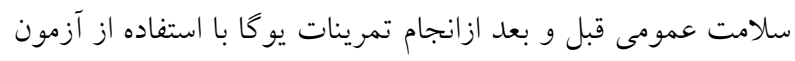

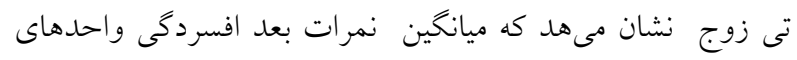

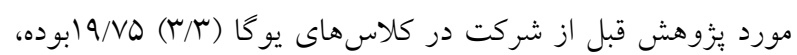

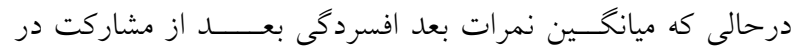

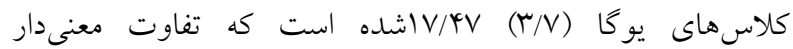

$$
\text { مى باشد. ( })
$$

دسته سوم تمرينات، تعمق يا مراقبه مى باشد كه به دو روش انجام گرديد. روش تمركزى و شيوه تفكرى. تعمق تمركزى فرد ياد

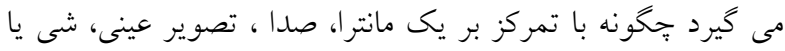

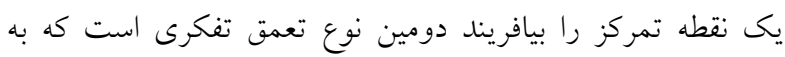

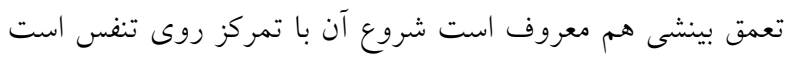

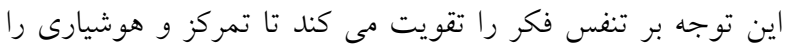

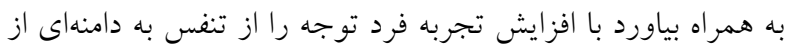

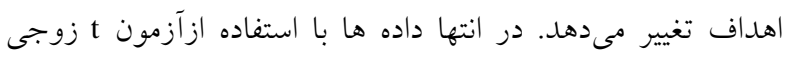
توسط نرمافزار اس بي اس اس ورزن الب مورد تجزيه و تحليل قرار تعداد •ll نفر از زنان ساكن شهر تهران در اين مطالعه شركت

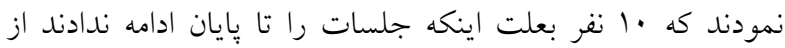

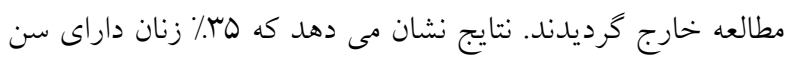

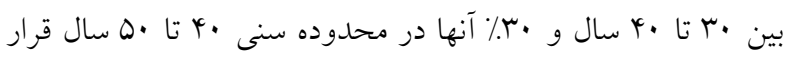

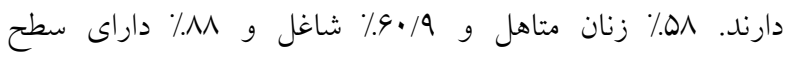

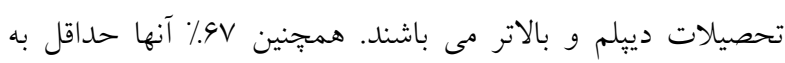
صورت دو بار در هفته تمرينات ورزشى مانند بياده روى را انجام

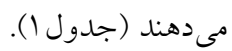
همان طور كه در جدول r نشان داده شده است، نتايج بعد

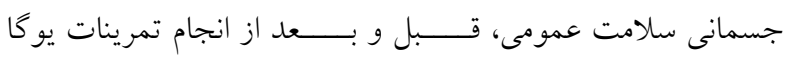

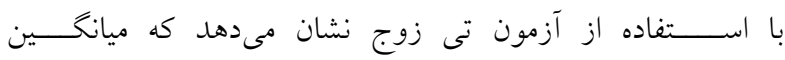

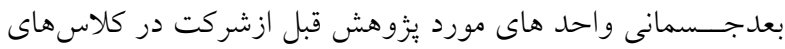

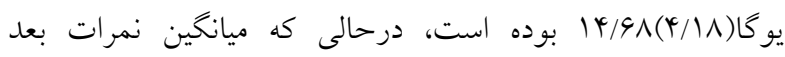

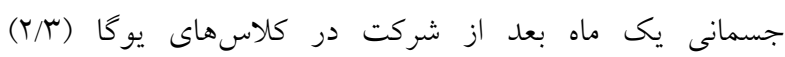

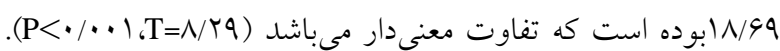
نتايج بعد اختلال اضطراب و خواب قبل و بعد ازاندان إنام تمرينات

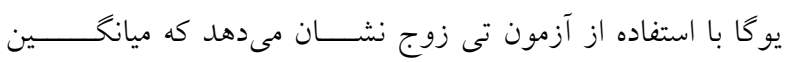

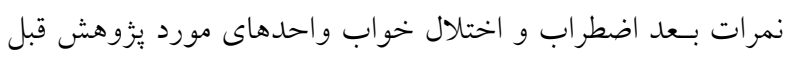

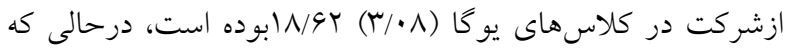

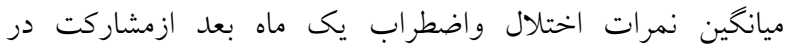

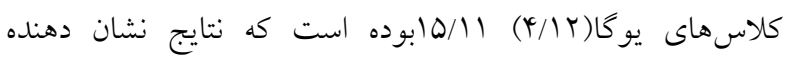

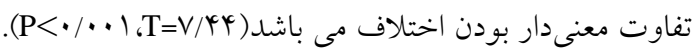


جدول r: ميانكين نمرات سلامت عمومى قبل و يك ماه بعد از آموزش

\begin{tabular}{|c|c|c|c|c|c|}
\hline \multirow[t]{2}{*}{ سطح معنى دارى } & \multirow[t]{2}{*}{$T$} & \multicolumn{2}{|c|}{ ميانكين (انحراف معيار) } & \multirow[t]{2}{*}{ تعداد } & \\
\hline & & بعد & قبل & & \\
\hline$p<\cdot / \cdot \cdot 1$ & $N / T 9$ & $V r / 19(N / Q 1)$ & $9 \cdot 119(1 \% / \cdot 1)$ & $1 \cdots$ & نمره كلى سلامت عمومى \\
\hline$p<\cdot / \cdot \cdot 1$ & $N / T a$ & N/99 (T/T) & $14 / 91(\% / 1 \Lambda)$ & $1 .$. & علايم جسمانى \\
\hline$p<\cdot / \cdot \cdot 1$ & $N / r$ & $19 / 1 \Gamma(Y / \Lambda)$ & $\mid r / q \cdot(r / 9 T)$ & $1 .$. & علايم اختلال عملكرد اجتماعى \\
\hline$p<\cdot / \cdot \cdot 1$ & $V / 4 \varphi^{4}$ & $10 / 11(Y / / T)$ & $\operatorname{MNGY}(r / \cdot 1)$ & $1 .$. & علايم اضطراب و اختلال خواب \\
\hline$p<\cdot / \cdot \cdot 1$ & $0 / r q$ & $\mid V / \mathscr{E V}(\Gamma / V)$ & 19/VQ $(\Gamma / \Gamma)$ & $1 .$. & علايم افسردگى \\
\hline
\end{tabular}

يوكا باعث افزايش تاب آورى و سلامت عمـومى زنـان كرديــــــا.

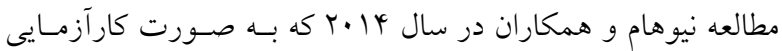

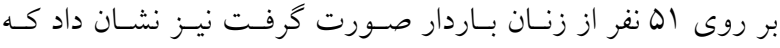

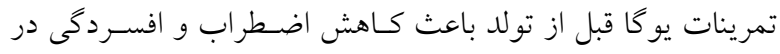

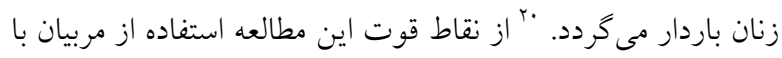

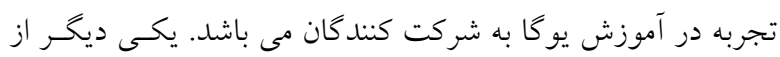

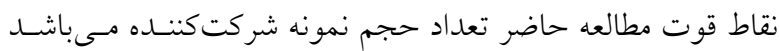

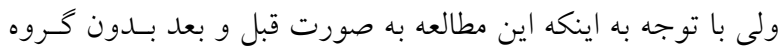

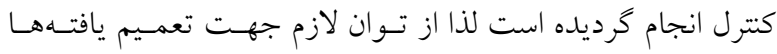

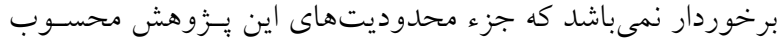

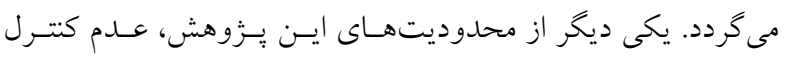

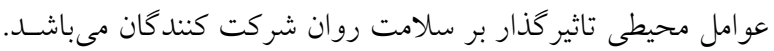

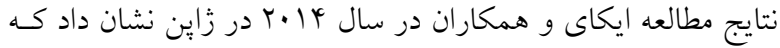
يو كاه نتوانسته بود باعث اختلاف معنىدارى در تـابآورى بيمـاران

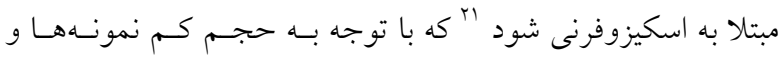

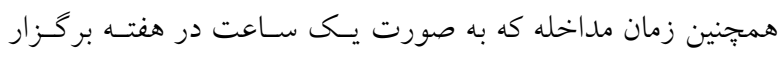
كرديد قابل توجيه مى باشد. شيفيلد و وودز در سال 19 •ب در مطاله اى كه به صورت مرور سيستماتيك بر روى مقالات منتشر شده تـا

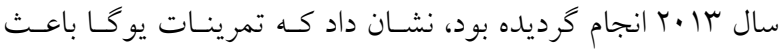

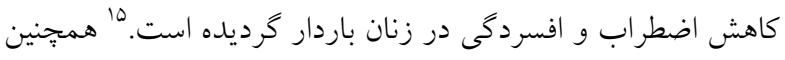

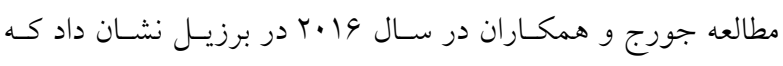

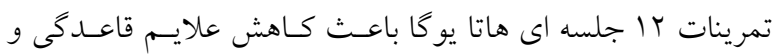

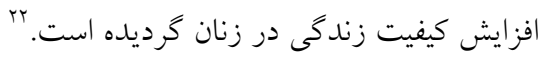

همجنين نتايج كلى سلامت عمومسى روان، قبل و بعد ازانجام

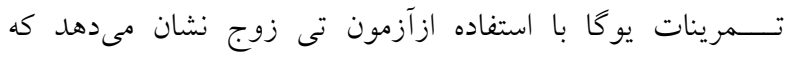

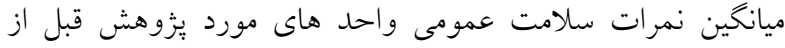

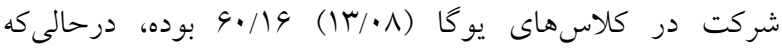

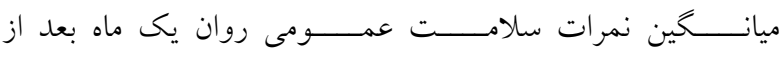

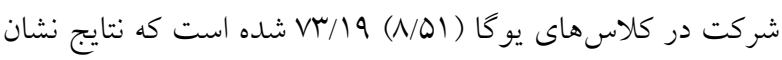

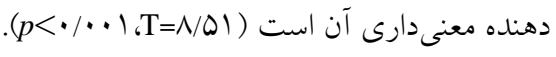

اين بزّوهش با هدف بررسى تاثير يوكا بر سـلامت روان زنسان

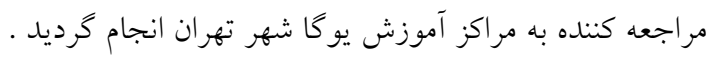

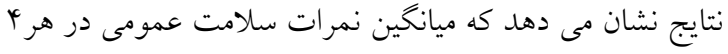

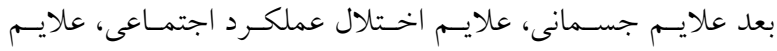

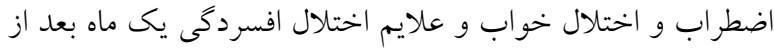

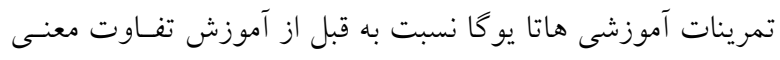

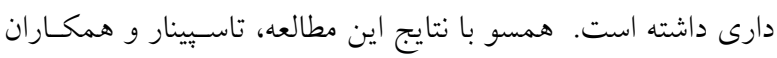
در مطالعه اى كه در سال ؟ أب بر روى بزركسالان ناتوان انجـام داد به اين نتيجه رسيد كه هاتا يو كامى تواند كيفيت زندكى، خستخكى و

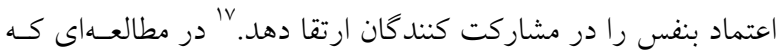

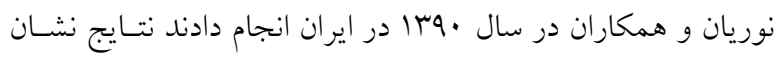

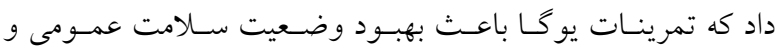

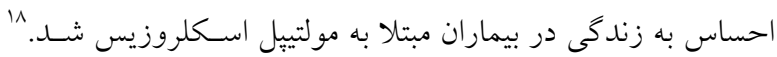

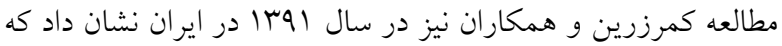




$$
\begin{aligned}
& \text { تعارض منافع } \\
& \text { نويسند كان اظهار مى دارند كه هـيج كونسه تعـارض منـافعى در } \\
& \text { انتشار نتايج اين مطالعه وجود نداشته است. }
\end{aligned}
$$

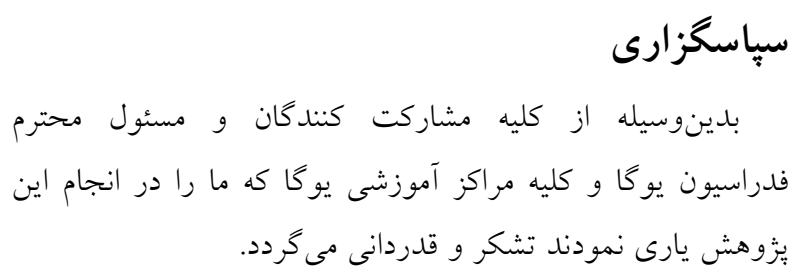

\section{References}

1. Hyman S, Chisholm D, Kessler R, Patel V, Whiteford H. Mental disorders. Disease control priorities related to mental, neurological, developmental and substance abuse disorders. The International Bank for Reconstruction and Development / The World Bank; New York: Oxford University Press; 2006. 2006:1-20.

2. Moussavi S, Chatterji S, Verdes E, Tandon A, Patel V, Ustun B .Depression, chronic diseases, and decrements in health: results from the World Health Surveys. The Lancet. 2007;370(9590):851-8.

3. Beesdo K, Knappe S, Pine DS. Anxiety and anxiety disorders in children and adolescents: developmental issues and implications for DSM-V. The Psychiatric clinics of North America. 2009 Sep;32(3):483-524. PubMed PMID: 19716988. Pubmed Central PMCID: 3018839.

4. Moraes LJ, Miranda MB, Loures LF, Mainieri AG, Mármora CHC. A systematic review of psychoneuroimmunology-based interventions. Psychology, health \& medicine. 2017:1-18.

5. Streeter C, Gerbarg P, Saper R, Ciraulo D, Brown R. Effects of yoga on the autonomic nervous system, gamma-aminobutyric-acid, and allostasis in epilepsy, depression, and post-traumatic stress disorder .Medical hypotheses. 2012;78(5):571-9.

6. Thayer J, Lane R. A model of neurovisceral integration in emotion regulation and dysregulation. Journal of affective disorders. 2000; 2(61):201-16.

7. Shroff FM, Asgarpour M. Yoga and Mental Health: A Review. Journal of Physiotherapy \& Physical Rehabilitation. 2017;02(01).

8. Shirley Telles M. Assessing depression following two ancient Indian interventions: effects of yoga and ayurveda on older adults in a residential home. Journal of gerontological nursing. 2007;17(2):33.

9. Janakiramaiah N, Gangadhar B, Murthy PNV, Harish M, Subbakrishna D, Vedamurthachar A. Antidepressant efficacy of Sudarshan Kriya Yoga (SKY) in melancholia: a randomized comparison with electroconvulsive therapy (ECT) and imipramine. Journal of affective disorders. 2000;57(1):255-9.
10. Sharma V, Das S, Mondal S, Goswami U, Gandhi A. Effect of Sahaj Yoga on depressive disorders. Indian 2005;49(4):462.

11. Cohen L, Warneke C, Fouladi RT, Rodriguez M, Chaoul-Reich A. Psychological adjustment and sleep quality in a randomized trial of the effects of a Tibetan yoga intervention in patients with lymphoma. Cancer. 2004;100(10):2253-60.

12. Chen K-M, Chen M-H, Chao H-C, Hung H-M, Lin H-S, Li C-H. Sleep quality ,depression state, and health status of older adults after silver yoga exercises: cluster randomized trial. International journal of nursing studies. 2009;46(2):154-63.

13. Parshad O. Role of yoga in stress management. The West Indian Medical Journal. 2004;53(3):191-4.

14. Ward L, Stebbings S, Cherkin D, Baxter GD. Components and reporting of yoga interventions for musculoskeletal conditions: A systematic review of randomised controlled trials. Complementary therapies in medicine. 2014;22(5):909-19.

15. Sheffield KM, Woods-Giscombé CL. Efficacy, feasibility, and acceptability of perinatal yoga on women's mental health and well-being: a systematic literature review. Journal of Holistic Nursing. 2016;34(1):64-79.

16. Ebrahimi AE, Moulavi H, Mousavi SG, BornaManesh A, of General Health Questionnaire 28 (GHQ-28) in Iranian psychiatric patients Journal of Research in Behavioural Sciences. 2007;5(1):5-11.[In Persian]

17. Taspinar B, Aslan UB, Agbuga B, Taspinar F. A comparison of the effects of hatha yoga and resistance exercise on mental health and well-being in sedentary adults: a pilot study. Complementary therapies in medicine . 2014 Jun;22(3):433-40. PubMed PMID: 24906581 .

18. Nouryan K, Malekzadeh G, Ghaem H, Roozitalab M, Afraseyabifar A, Moghimi M, et al. Effect of yoga exercise on general health status (GHS) and sense of life in patients with multiple sclerosis. Armaghane danesh. 2011;16(3):245-53.[In Persian] Journal of Physiology and Pharmacology Yaghoubi M. Psychometric properties and factor structure 
19. Kamarzarrin H, Shooshtari M, Badripor M, Khosravani F. Effect of Yoga on the components resiliency and psychological well-being of women in Isfahan Health Psychology. 2012;1:3

20. Newham JJ, Wittkowski A, Hurley J, Aplin JD, Westwood M. Effects of antenatal yoga on maternal anxiety and depression: a randomized controlled trial. Depression and anxiety. 2014;31(8):631-40. PubMed PMID: 24788589.

21. Ikai S, Suzuki T, Uchida H, Saruta J, Tsukinoki K, Fujii Y, et al. Effects of weekly one-hour Hatha yoga therapy on resilience and stress levels in patients with schizophrenia-spectrum disorders: an eight-week randomized controlled trial. The Journal of Alternative and Complementary Medicine. 2014;20(11):823-30.

22. Jorge MP, Santaella DF, Pontes IM, Shiramizu VK, Nascimento EB, Cabral A, et al. Hatha Yoga practice decreases menopause symptoms and improves quality of life: A randomized controlled trial. Complementary therapies in medicine. 2016 Jun;26:128-35. PubMed PMID: 27261993. 